\title{
La organización campesina y algunas propuestas para su desarrollor
}

\author{
Aquiles Montoya
}

\section{Resumen}

Puesta al día de la existencia y del estado de las organizaciones campesinas. El autor hace un breve recorrido por dichas organizaciones, dando cuenta de sus recomposiciones y de su situación actual. Este ejercicio le lleva a algunas conclusiones y, lo más importante, a presentar propuestas.

Lo primero que se debe de tener en cuenta de cara a una estrategia campesina es la heterogeneidad de su composición, lo cual no niega que existan problemas comunes.

1. Antecedentes del movimiento campesino: composiciones y recomposiciones 2

Resulta interesante observar la evolución de las organizaciones campesinas así como sus respectivos agrupamientos y reagrupamientos, más en función de intereses políticos e ideológicos que gremiales o reivindicativos. En cuanto a sus intereses gremiales, si bien han presentado cierta modificación en razón de los cambios experimentados por la realidad social - la reforma agraria-, también se observan cambios en razón de la actualización de otros problemas -lo ecológico, el género- o bien, debido a los énfasis dados a uno u otro problema --sindicalización campesina, mejores salarios, etc. Pese a ello, existe una problemática permanente vinculada a la carencia de tierra o a la conservación de la misma. La relación hombre-tierra es una problemática constante entre los campesinos.

\subsection{La década de los setenta}

Las organizaciones campesinas que más se destacaron durante este período fueron la Federación Cristiana de Campesinos Salvadoreños (FECCAS) y la Unión de Trabajadores del Campo (UTC), ambas conformaron posteriormente la Federación de Trabajadores del Campo (FTC) y ulteriormente, constituyeron la base social más importante del Bloque Popular Revolucionario (BPR), el frente de masas de las Fuerzas Populares de Liberación (FPL). 
Su actividad reivindicativa estuvo marcada por la libre sindicalización campesina, el acceso a la tierra, la mejora de los salarios y las condiciones de trabajo, así como también la disminución de los cánones de arrendamiento, de los precios de los insumos y de las tasas de interés de los créditos de avío. Ciertamente, la problemática ecológica y de género estaba ausente en sus líneas de acción, como lo estaban también en el movimiento social a nivel nacional.

\subsection{La década de los ochenta}

Durante este período, las organizaciones campesinas vinculadas a la izquierda desaparecieron de la escena sociopolítica, ya sea porque se las obligó a emigrar o porque se incorporaron a la lucha político militar. Entonces, el escenario fue ocupado por otras organizaciones que, si bien ya existían desde la década pasada, no habían tenido un mayor protagonismo político. Y es que durante la década de los sesenta, en el marco de la Alianza para el Progreso, se buscó desactivar la tensión social en el campo mediante la creación de cooperativas. Este esfuerzo resultó inútil y lo único que generó fue cierta desconfianza hacia el cooperativismo de parte de los sectores de izquierda, prejuicio que afortunadamente ya fue superado.

En un primer momento, la mayor fuerza social de base campesina fue la Unidad Popular Democrática (UPD) 3 , luego le siguen la Unión Nacional de Trabajadores Salvadoreños (UNTS) y la Unión Nacional de Obreros y Campesinos (UNOC).

La Unidad Popular Democrática (UPD) la constituyeron las organizaciones campesinas siguientes4: la Unión Comunal Salvadoreña (UCS), la Central de Trabajadores del Campo (CTS), las Asociaciones Cooperativas Agropecuarias Integradas (ACOPAI), la Asociación Nacional Indígena Salvadoreña (ANIS) y la Central Campesina Salvadoreña (CCS).

La principal base social campesina de la Unidad Popular Democrática provenía de la Unión Comunal Salvadoreña, a cuyo secretario general se le concedió la presidencia del Instituto Salvadoreño de Transformación Agraria (ISTA). Ulteriormente, éste fue víctima de los escuadrones de la muerte.

Entre sus demandas relacionadas con los intereses campesinos, podemos mencionar: la creación de un nuevo Código de Trabajo, donde se destaca- ba el derecho a la huelga y a la libre asociación de los trabajadores del campo y la ciudad; la ratificación de los convenios de la Organización Internacional del Trabajo; operativizar la reforma agraria, la nacionalización de la banca y del comercio exterior así como programas intensivos de producción agropecuaria, etc.

La Unidad Popular Democrática apoyó al Partido Demócrata Cristiano en las elecciones de marzo de 1982 y en las presidenciales de 1984, en base al llamado "pacto social". En virtud del pacto, la organización obtuvo algunos puestos públicos para sus dirigentes, al resultar electo presidente Napoleón Duarte. Pero a raíz del carácter marcadamente impopular de la política económica emprendida por el gobierno de Duarte, la Unidad Popular Democrática se vio obligada a romper el "pacto social", quedándose como una fuerza independiente, pero con poca presencia en el quehacer sociopolítico nacional. Algunas de sus organizaciones se separaron y posteriormente dieron un viraje inesperado y aparecieron formando parte de un nuevo agrupamiento social claramente antigobiernista y pro-izquierda -la Unión Nacional de los Trabajadores Salvadoreños (UNTS)5-, junto a la Confederación de Asociaciones Cooperativas de El Salvador (COACES), la Central de Trabajadores Salvadoreños (CTS)6, y otras organizaciones de trabajadores urbanos del sector público y privado. Pero su presencia fue efímera y aunque algunas de sus organizaciones continuaron en la Unión Nacional de los Trabajadores Salvadoreños, otras pasaron a ser parte de la Unión Nacional de Obreros y Campesinos. En la actualidad, a juicio de algunos analistas, la Unidad Popular Democrática está totalmente desarticulada, conservando únicamente "el cascarón", pues carece de base social.

Cuando las organizaciones afines a la izquierda intentaron reagruparse, el Partido Demócrata Cristiano y el Instituto Americano para el Desarrollo del Sindicalismo Libre maniobraron. Así, en marzo de 1986, a cuatro semanas de haber conformado la Unidad Nacional de Trabajadores Salvadoreños surgió la Unión Nacional de Obreros y Campesinos, constituida por las organizaciones siguientes7: la Federación Salvadoreña de Cooperativas de la Reforma Agraria (FESACORA), la Federación de Cooperativas de la Reforma Agraria de la Región Occidental (FECORASAL), la Federación de Cooperativas de la Reforma Agraria de 
la Región Central (FECORACEN), la Central Campesina Salvadoreña (CCS) y algunos disidentes de la Asociación Nacional de Indígenas Salvadoreños y de la Unión Comunal Salvadoreña.

Entre sus demandas relacionadas con el sector campesino, se pueden mencionar: la profundización de la reforma agraria, la agilización de los créditos agrícolas y la disminución de los precios de los insumos agrícolas.

En 1989, de las bases de la Unión Nacional de Trabajadores Salvadoreños 8 y de la Unión Nacional de Obreros y Campesinos ${ }^{9}$ surgieron la Alianza Democrática Campesina, la cual representa en la actualidad, seguramente, el agrupamiento campesino más importantes de la historia nacional. Y en ello mucho tiene que ver el auge cobrado por el movimiento cooperativista.

\section{La organización campesina actual}

En la actualidad, el agrupamiento campesino más importante es la Alianza Democrática Campesina (ADC), lo cual no excluye la existencia de otras organizaciones tales como: la Unión Comunal Salvadoreña (UCS), la Central de Trabajadores del Campo, las Asociaciones Cooperativas de Producción Agropecuarias Integradas (ACOPAI), así como muchas cooperativas no federadas.

\subsection{Alianza Democrática Campesina}

Tal como su nombre lo indica, la Alianza Democrática Campesina es una alianza que se fundamenta en la concertación de intereses, objetivos, ideas y soluciones a la problemática histórica del campesino salvadoreño. La organización se conformó en octubre de 1989. Sus ejes de trabajo en la actualidad son la tierra, el crédito, la comercialización, el medio ambiente, la mujer, los derechos humanos y la educación 10 .

Al ser una organización exclusivamente campesina, sus demandas se vuelven mucho más precisas de cara a los intereses del trabajador del campo. Así, inicialmente planteaban la defensa de la reforma agraria, mayor acceso a la tierra, créditos en condiciones favorables, mejores precios para los productos agrícolas, condonación de la deuda agraria y bancaria, tecnología adecuada, sindicalización campesina, etc.

Pero en un documento titulado "Propuesta de plataforma de la Alianza Democrática Campesina para el desarrollo campesino sostenible y el rescate del medio ambiente en El Salvador", auspiciado por el Comite de Acción de Apoyo al Desarrollo Económico y Social de Centroamérica (CADESCA), se señala que "los problemas que más afectan a la población rural del país son: la tenencia de la tierra, el crédito, la comercialización de la producción, los bajos niveles educativos y la falta de información técnica, la incapacidad de agregar valor a los productos agropecuarios y la degradación del medio ambiente". En correspondencia con este diagnóstico se formula la "Estrategia de desarrollo campesino sostenible"11, la cual, unida a sus ejes de trabajo actuales, sugiere dos hechos importantes: la conformación mayoritaria de los integrantes de la Alianza Democrática Campesina12 está sesgando la orientación y las prioridades de su actividad y, derivado de éste, los intereses del obrero agrícola y del proletario campesino están siendo descuidados.

En 1995, la Alianza Democrática Campesina tenía registradas 26 organizaciones campesinas, a saber:

(a) asociaciones campesinas: Asociación Nacional de Trabajadores Agropecuarios (ANTA), Asociación Salvadoreña de Indígenas Democráticos (ASID), Asociación Democrática Campesina (ADEC), Asociación Comunal Campesina de Occidente (ACCO), Asociación Salvadoreña de Desarrollo Comunal (ASDEC);

(b) centrales campesinas: Central Campesina Salvadoreña (CCS);

(c) uniones campesinas: Unión Nacional de Trabajadores Agropecuarios (UNATA), Unidad Popular Democrática (UPD no gubernamental);

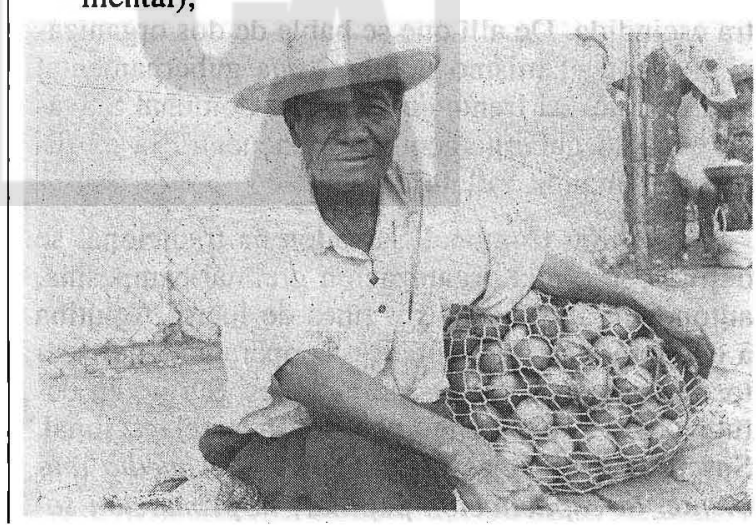


(d) sector cooperativo reformado: Federación de Cooperativas de la Reforma Agraria Salvadoreña (FECORASAL), Federación de Cooperativas de la reforma Agraria Región Central (FECORACEN), Federación de Cooperativas de la Reforma Agraria Región Paracentral (FECORAPCEN), Federación de Cooperativas de la Reforma Agraria de Oriente (FECORAO), Confederación de Federaciones de la Reforma Agraria Salvadoreña (CONFRAS), Federación Salvadoreña de Cooperativas de la Reforma Agraria (FESACORA);

(e) Sector cooperativo tradicional: Federación de Cooperativas de Producción Agropecuaria Salvadoreña (FEDEPAS), Federación de Cooperativas Agropecuarias Salvadoreñas (FECOAS), Federación de Cooperativas Indígenas Agropecuarias Salvadoreñas (FECOIAS), Federación Nacional de Cooperativas de Producción Agropecuaria Salvadoreñas (FENACOOPAS), Federación Nacional de Cooperativas Agropecuarias (FENACOA);

(f) Sector sindical campesino: Sindicato de Trabajadores Agropecuarios Salvadoreños (SITAS);

(g) Organismos de participación eventual: Comunal Salvadoreña (UCS, no gubernamental), Cooperativa "El Espino" de R.L., Federación de Cooperativas de Producción Agropecuaria de Guazapa (FEDECOOPAG), Federación de Cooperativas de Desarrollo Agropecuario de El Salvador (FECODAES), Asociación Nacional Campesina (ANC), Asociación de Trabajadores Agropecuarios de El Salvador (ATAES).

\subsection{La Unión Comunal Salvadoreña (UCS)}

La Unión Comunal Salvadoreña es una organización campesina que en la actualidad se encuentra escindida. De allí que se hable de dos organizaciones con el mismo nombre, una gubernamental y la otra no. Al frente de la Unión Comunal Salvadoreña (no gubernamental) se encuentra la ex diputada Amanda Villatoro.

La Unión Comunal Salvadoreña tradicional se define como una organización gremial campesina, autónoma, apolítica y sin fines de lucro. Aglutina a cooperativas tradicionales, cooperativas del sector reformado y socios individuales. Surgió en octubre de 1971 y tiene cobertura a nivel nacional. Sus principales ejes de trabajo son el medio ambiente, la capacitación popular, la promoción so- cial, el acceso a la tierra, el acceso al crédito, la integración familiar y el desarrollo integral comunitario 13.

En razón de la división experimentada, no deja de ser cuestionable el número de 28,300 asociados que dice tener14. Sin embargo, entre ambas organizaciones, posiblemente aglutinen a más de 30 mil socios, lo cual la convierte en una fuerza social campesina importante 15 .

\subsection{La Central de Trabajadores del Campo (CTC)}

Esta organización nació durante los años de la guerra y busca aglutinar un amplio espectro de organizaciones campesinas, tales como cooperativas, asociaciones comunales, sindicatos, asociaciones agropecuarias, etc. Una de sus principales dirigentes es Rosario Acosta.

Entre sus objetivos cabe mencionar fomentar el desarrollo y fortalecimiento de la conciencia solidaria del campesino salvadoreño, contribuir a la promoción y al fortalecimiento de los sectores reformado y no reformado, promover la organización y el desarrollo integral de la mujer campesina y la juventud rural, velar por la defensa y el desarrollo del pequeño y mediano agricultor, incidir en las políticas orientadas al sector agropecuario, etc. 16 .

\subsection{La Confederación de Federaciones de Coo- perativas de la Reforma Agraria Salvado- reña (CONFRAS)}

Esta confederación la fundaron cuatro federaciones de cooperativas de la primera fase de la reforma agraria, en 1988. Actualmente agrupa a ocho federaciones, de las cuales la mayoría siguen siendo las cooperativas de la primera fase, pero también se han agregado cooperativas de la tercera fase y un 10 por ciento de las cooperativas tradicionales.

Entre su objetivos cabe destacar la defensa, consolidación y profundización del proceso de reforma agraria, el modelo de producción cooperativo y el carácter autogestivo de las empresas campesinas, el desarrollo de un proceso sostenido de educación cooperativa y de capacitación técnica para la producción, la recuperación productiva y el desarrollo económico de las cooperativas, etc.

Sus ejes estratégicos son la organización, la formación y la capacitación, la producción y la defensa de la tierra17. 


\subsection{La Confederación de Asociaciones Coope- rativas de El Salvador (COACES)}

Debido a que esta confederación no aglutina exclusivamente a cooperativas agrarias, nos ocuparemos de las dos federaciones que agrupan trabajadores del campo: la Federación Salvadoreña de Cooperativas de la Reforma Agraria (FESACORA) y FEDECOOPADES.

La primera surgió en 1982, aglutinando exclusivamente a cooperativas de la primera fase de la reforma agraria a nivel nacional. Entre sus objetivos actuales encontramos: contribuir a la consolidación del proceso de reforma agraria, procurar el mejoramiento social y económico de sus afiliados, de tal manera que sean entes dinamizadores del desarrollo nacional, fomentar la integración del sector agropecuario, etc. Sus actividades principales están orientadas a la capacitación, la asistencia técnica, la promoción y la comercialización. Dentro de sus programas cabe destacar los bancos comunales, dirigidos exclusivamente a las mujeres vinculadas a las cooperativas-socias, esposas o hijas de socios 18 .

FEDECOOPADES se fundó en 1979, o sea, en la fase previa a la reforma agraria, por lo tanto, surgió como parte de las cooperativas tradicionales. Sus objetivos son semejantes a los de FESACORA. Entre los servicios que prestan a sus afiliados están la asistencia técnica, la promoción y la organización cooperativa, el desarrollo empresarial, la asesoría jurídica, la asistencia social, etc. 19.

\subsection{La organización comunal}

Además de las organizaciones campesinas anteriores también es posible incluir dentro del movimiento social rural a las organizaciones de las comunidades de repobladores y repatriados, el fenómeno más novedoso de cara al siglo XXI. La organización de primer nivel es la asociación comunal, la cual es reconocida por el Código Municipal, pero a su vez las diferentes asociaciones comunales se agrupan en organizaciones de segundo y tercer grado.

\subsubsection{La Corporación de Comunidades Rura- les para el Desarrollo de El Salvador (CRIPDES)}

Esta corporación surgió como un Comité Cristiano Pro-Desplazados de El Salvador en 1984. En
1995 se convirtió en la Corporación de Comunidades Rurales para el Desarrollo de El Salvador, pero sigue conservando las siglas de CRIPDES.

Está integrada por cinco organismos regionales, a saber: la Coordinadora de Comunidades y Repoblaciones (CCR), en Chalatenango; la Promogestora de Repoblaciones Solidarias (PROGRESO), en Cuscatlán y Cabañas; la Unión de Comunidades y Repoblaciones (UCRES), en el norte de San Salvador y La Libertad; el Comité de Desplazados y Marginados (CODESMA), en La Libertad y la Corporación Comunal para el Desamollo Rural (CDR), en la región paracentral. Actualmente, CRIPDES acompaña a 168 comunidades en nueve departamentos del país 20 .

De la misma manera, existen otras organizaciones de comunidades, tales como el Comité de Reconstrucción de Chalatenango (CRCH), el Comité de Reconstrucción de Usulután (CRU), el Comité de Reconstrucción de Guazapa (CRG), los cuales están agrupados en la Coordinadora de Reconstrucción y Desarrollo. Dentro de esta coordinadora, merece destacarse la existencia de la Federación Intercomunal Guillermo Manuel Ungo, integrada por nueve comunidades de repobladores y ex combatientes del FMLN.

Además de las organizaciones antes mencionadas, hay otras comunidades que, por distintas razones, no forman parte de una organización de segundo grado. Entre ellas y a manera de ejemplos, podemos mencionar la Segundo Montes, en Morazán; Santa Marta, en Cabañas; y Nueva Esperanza y Ciudad Romero, en Usulután. No pueden dejar de mencionarse las organizaciones creadas por los ex combatientes del FMLN y los desmovilizados de la Fuerza Armada, las cuales están constituidas, fundamentalmente, por campesinos.

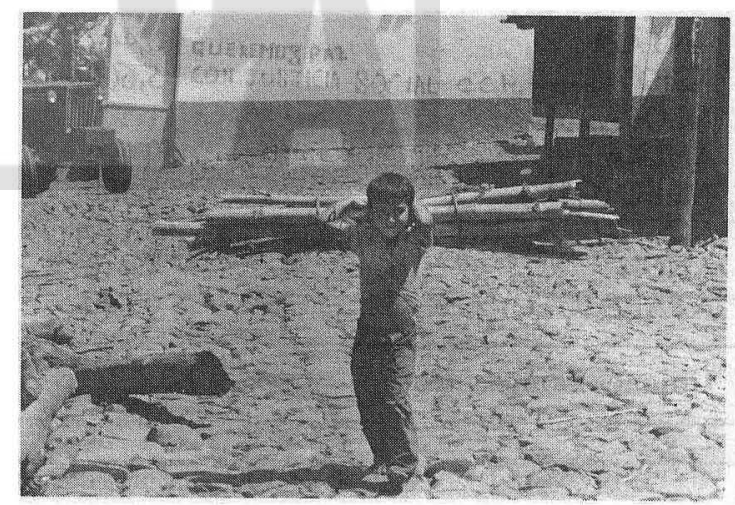




\section{Estimación de la organización campesina}

Es difícil estimar el estado actual de la organización campesina. Esto no hubiera sido posible sin la valiosa colaboración de Obdulio Palacios, a quien expresamos nuestro agradecimiento.

El número de socios indicado arriba proviene de las mismas organizaciones - cuando éste no es el caso, se señala expresamente. No pretendemos haber agotado esta tan necesaria estimación de la población organizada en el agro. Seguramente existen algunas organizaciones que no logramos detectar y, consiguientemente, nos se les pudo pasar el cuestionario diseñado para tal propósito. Adicionalmente, es probable que en algunos casos haya duplicidad en la cuantificación de los socios, aunque se hemos tratado de evitarla al constatar que una asociación formaba parte de otra organización mayor. Sin embargo y pese a las deficiencias no detectadas, creemos haber cubierto la gran mayoría de

El mayor número de campesinos organizados en el agro salvadoreño se encuentra asociado en cooperativas las organizaciones y, por lo tanto, los datos que presentamos son representativos del movimiento campesino organizado. En cualquier caso, las omisiones pueden estar compensadas con las sobreestimaciones.

Indudablemente, con más tiempo y mayores recursos, se puede profundizar en este estudio.
Con todo, pensamos haber creado una base de datos a partir de la cual será mucho más fácil continuar el trabajo investigativo, ya sea para profundizar o para actualizarlo.

Existen tres modalidades de organización rural, las asociaciones tradicionales de socios individuales, las asociaciones cooperativas -incluyendo a los grupos precooperativos- integradas en federaciones y confederaciones y las asociaciones comunales. De las tres, la última es la más novedosa.

Se observa cierta tendencia hacia la organización cooperativa. Así, por ejemplo, la Asociación Nacional de Trabajadores Agropecuarios (ANTA), que se presenta como una organización tradicional de campesinos individuales, incluye entre sus asociados a grupos cooperativos y precooperativos. Así como ANTA hay otras muchas organizaciones de campesinos. A su vez, las asociaciones comunales conforman a su interior asociaciones

cooperativas.

El mayor número de campesinos organizados en el agro salvadoreño se encuentra asociado en cooperativas. Y finalmente, como una resultante de lo anterior cabe señalar que es necesario fortalecer la organización del campesino proletario y del proletario agrícola21.

\section{Cuadro 1}

Principales organizaciones campesinas y sus socios (1995)

\begin{tabular}{lrcc}
\hline Tipo de organización & Número de socios & Beneficiarios22 & Cooperativas \\
\hline Asociaciones campesinas & & & \\
\hline ANTA23 & 16,447 & 82,235 & 52 \\
ASID24 & 5,600 & & 25 \\
ACOPAI25 & 1,509 & 7,545 & 47 \\
ANIS26 & 60,125 & 27,000 & 22 \\
ADEC (CTC) & 5,400 & 25,750 & 35 \\
ACCO27 & 5,150 & 6,080 & 17 \\
ANC28 & 1,216 & 30,000 & \\
ATAES (CTC)29 & 6,000 & & \\
\hline
\end{tabular}

\section{Uniones campesinas}




\begin{tabular}{|c|c|c|c|}
\hline Tipo de organización & Número de socios & Beneficiarios & Cooperativas \\
\hline UNATA & 2,000 & 10,000 & \\
\hline UCS (no gubernamental) & 6,747 & 33,735 & 101 \\
\hline UCS & 28,300 & 141,500 & \\
\hline UPD (no gubernamental) & 1,500 & 7,500 & \\
\hline \multicolumn{4}{|l|}{ Confederaciones } \\
\hline CONFRAS: & 20,736 & 103,680 & 331 \\
\hline FECORASAL & 4,905 & 24,525 & 39 \\
\hline FECORACEN & 1,828 & 9,140 & 33 \\
\hline FECORAPCEN & 1,902 & 9,510 & 46 \\
\hline FECORAO & 3,458 & 17,290 & 59 \\
\hline FECOAS & 667 & 3,335 & 27 \\
\hline FENACOA & 4,128 & 20,640 & 52 \\
\hline FECOIAS & 838 & 4,190 & 26 \\
\hline $\mathrm{CCS}$ & 3,010 & 15,050 & 49 \\
\hline \multicolumn{4}{|l|}{ COACES: } \\
\hline FESACORA & 20,045 & 100,265 & 180 \\
\hline FEDECOOPADES30 & 3,361 & 24,000 & 51 \\
\hline FEDECOPPS & 1,050 & 5,250 & 22 \\
\hline \multicolumn{4}{|l|}{ No confederadas } \\
\hline FEDEPAS (CTC) & 2,400 & 12,000 & 42 \\
\hline FENACOOPAS (CTC) & 2,500 & & 10 \\
\hline FECASAL 31 & 118 & 590 & 2 \\
\hline FEDECAS 32 & 2,990 & 14,950 & 16 \\
\hline Cooperativas no federadas 33 & 12,213 & 61,065 & 100 \\
\hline $\begin{array}{l}\text { Organizaciones } \\
\text { comunales }\end{array}$ & $\begin{array}{l}\text { Número de } \\
\text { familias }\end{array}$ & $\begin{array}{l}\text { Número de } \\
\text { comunidades }\end{array}$ & $\begin{array}{l}\text { Número de } \\
\text { municipios }\end{array}$ \\
\hline CRIPDES34: & 15,436 & 168 & 32 \\
\hline CCR & 8,600 & 43 & 12 \\
\hline CDR & 2,534 & 35 & 3 \\
\hline PROGRESO & 2,335 & 31 & 4 \\
\hline CODESMA & 550 & 18 & 6 \\
\hline UCRES & 1,275 & 17 & 4 \\
\hline San Miguel & 142 & 3 & 3 \\
\hline \multicolumn{4}{|l|}{ Atendidas por } \\
\hline FUNSALPRODESE en: & & & \\
\hline San Miguel y Usulután & 2,321 & 19 & 9 \\
\hline Otras comunidades: & 20,000 & & \\
\hline \multicolumn{4}{|l|}{$\begin{array}{l}\text { Algunos sindicatos } \\
\text { agroindustriales }\end{array}$} \\
\hline SINA35 & 2,500 & & \\
\hline SITAS & 800 & & \\
\hline
\end{tabular}

Fuente: Elaboración propia en base a trabajo de campo, septiembre-octubre de 1995. 
El total de personas organizadas la estimamos en 318,678 , suponiendo que en las comunidades al menos dos personas de cada familia pertenecen a una organización. Sin embargo, el número de organizados que indica la Asociación Nacional de Indígenas Salvadoreños, nos parece excesivo. Por eso preferimos estimarlo en un tercio de lo registrado, esto es, en sólo 20 mil. Siendo así, el total de organizados se reduciría a 278,678. De éstos, estimamos que, al menos 110 mil están asociados en cooperativas, 93,164 de manera individual y 75,514 en comunidades. O sea que el 39.5 por ciento está organizado en cooperativas, el 33.4 por ciento de manera individual y el restante 27.1 por ciento en comunidades.

Esta es preciso tener en mente esta realidad de cara a una propuesta hacia el sector campesino salvadoreño, ya que si bien los problemas y las necesidades son comunes, también presentan diferencias significativas, las cuales es preciso considerar.
Antes de concluir este apartado quisiéramos hacer algunas referencias a las cooperativas del sector reformado de la primera fase, las cuales revelan algunos datos interesantes. El primero es que en 1993 y 1994 había 307 cooperativas, con un total de 28,893 socios, de los cuales el 87.12 por ciento eran hombres y el 12.8 por ciento mujeres. En segundo lugar, La Libertad es el departamento que cuenta con el mayor número de cooperativas $(57)$ y socios $(5,680)$, mientras que Cabañas y Morazán apenas tienen dos cooperativas cada uno y 79 y 123 socios, respectivamente. Finalmente, el promedio nacional de socios por cooperativa es de 94 (ver el Cuadro 2).

Ciertamente, es muy importante que casi el 13 por ciento de los asociados en las cooperativas de la primera fase de la reforma agraria sean mujeres. Aunque la proporción es todavía pequeña, en términos absolutos representa casi 4 mil socias.

\section{Cuadro 2}

Socios y cooperativas de la reforma agraria, Fase I (1993-1994)

\begin{tabular}{lrrrrr}
\hline Departamento & Hombres & Mujeres & Asociados & No.Coop & Socios/Coop \\
\hline Santa Ana & 2,168 & 134 & 2,302 & 23 & 100 \\
Ahuachapán & 2,634 & 380 & 3,014 & 28 & 107 \\
Sonsonate & 4,104 & 452 & 4,556 & 36 & 126 \\
La Libertad & 4,764 & 916 & 5,680 & 57 & 99 \\
San Salvador & 1,143 & 147 & 1,290 & 13 & 99 \\
Chalatenango & 754 & 26 & 780 & 9 & 69 \\
Cuscatlán & 177 & 30 & 207 & 3 & 39 \\
Cabañas & 74 & 5 & 79 & 2 & 56 \\
San Vicente & 450 & 110 & 560 & 10 & 83 \\
La Paz & 3,292 & 524 & 3,816 & 46 & 74 \\
Usulután & 2,751 & 723 & 3,494 & 37 & 71 \\
San Miguel & 1,735 & 134 & 1,869 & 25 & 61 \\
La Unión & 1,022 & 121 & 1,143 & 16 & 2 \\
Morazán & 103 & 20 & 123 & 307 & \\
\hline Total & 25,171 & 3,722 & 28,893 & & \\
\hline
\end{tabular}

$\begin{array}{llll}\text { Porcentaje } & 87.12 & 12.8 & 100.0\end{array}$

Socios por cooperativa

Fuente: Noveno censo agropecuario de las cooperativas del sector reformado, 1993-1994. 


\section{Conclusiones y propuestas}

Primera conclusión. Dada las características particulares de la población rural, la mejor forma para aproximarse a la oferta de trabajo en el agro es refiriéndose a la población en edad de trabajar (PET), la cual para 1992, la estimábamos en 1.8 millones. De ese gran total, están ocupados $920,835,535,983$ en el agro y 287,351 en otros sectores de la actividad económica.

Segunda conclusión La importancia económica del sector agrario presenta una tendencia declinante en el período de 1990 a 1994. Sin embargo, la producción de granos bá-

\section{La importancia económica del sector agrario presenta una tendencia declinante en el período de 1990 a 1994.}

sicos representa un quinto del PIB agropecuario y tiende a permanecer estable, lo cual indica que ante la crisis de los productos tradicionales de exportación, los cuales son cultivados en explotaciones, generalmente capitalistas, las formas empresariales no capitalistas tienden a fortalecerse y a preservarse.

Tercera conclusión. La estructura empresarial en el agro, integrada por campesinos proletarios, pequeños y medianos campesinos, cooperativistas, pequeños, medianos y grandes empresarios capitalistas, es un factor de sumo interés para comprender mejor la realidad agraria. Cabe destacar dos elementos: el carácter estacional del empleo y los bajos salarios, los cuales son insuficientes, incluso para satisfacer las necesidades alimentarias.

Cuarta conclusión. Llama poderosamente la atención el hecho de que las cifras oficiales indiquen niveles de ocupación muy bajos para la mujer en el agro. Así tenemos que, en 1991 y 1993 , tan sólo representaron el 10.2 y 16.1 por ciento respectivamente de los ocupados en el sector. En cambio, en los otros sectores representaron, en los mismos años, el 51.8 y el 52.1 por ciento respectivamente.

Quinta conclusión. La organización campesina muestra una larga trayectoria, constituyendo la base social de los movimientos políticos más importantes del siglo, desde el de 1932 hasta los de la década de los ochenta.

Sexta conclusión. En las décadas de 1960 ,

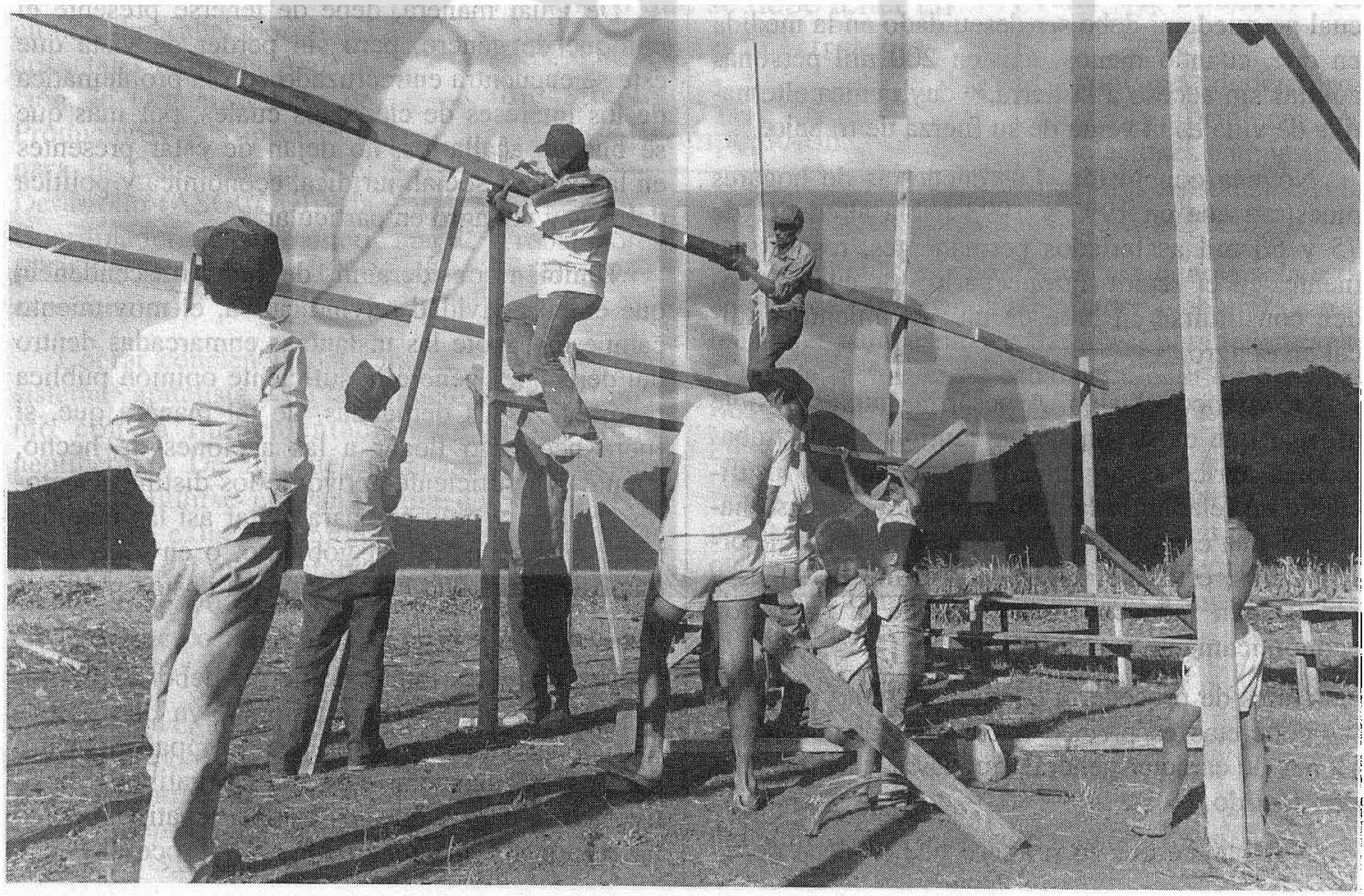


1970 y 1980 las principales reivindicaciones campesinas estuvieron asociadas a la demanda de tierra, mejores salarios, sindicalización campesina, créditos, mejores precios para los insumos y los productos agrícolas, etc. En la presente década se han incorporado nuevas temáticas: la defensa de la reforma agraria, la condonación de las deudas, la tecnología adecuada, la problemática de género y la ecológica.

Séptima conclusión. Se observan nuevas formas de organización campesina. A la par de las asociaciones campesinas tradicionales, han aparecido las asociaciones cooperativas - al menos, en forma numéricamente significativa- y las comunidades organizadas, lo cual significaría un nuevo contexto de cara a una estrategia campesina. Según nuestras estimaciones, los campesinos organizados presentan la estructura siguiente: el 39.5 por ciento está organizado en cooperativas, el 33.4 por ciento de manera individual y el restante 27.1 por ciento en comunidades.

Octava conclusión. La mayor presencia de las organizaciones cooperativas está llevando al movimiento campesino a descuidar algunas de sus demandas tradicionales como la sindicalización campesina y mejores remuneraciones salariales, lo cual no puede ni debe ser descuidado en la medida en que, cuando menos, existen 200 mil personas adultas sin acceso a la tierra, 36 cuya única alternativa de vida es la venta de su fuerza de trabajo.

Novena conclusión. Las encuestas de hogares muestran que en 1992 y 1993 había alrededor de 75 y 60 mil asalariados permanentes, respectivamente, en el sector agropecuario, los cuales pueden constituirse en base de un movimiento sindical en el agro.

Décima conclusión. A pesar de que es posible afirmar que existe un fuerte contingente de trabajadores agrícolas organizados, éste aún es insuficiente en relación a la población rural. Incluso haciendo una estimación optimista del número de organizados, éstos no pasan de 300 mil personas y representan menos de un tercio de la población económicamente activa (PEA).

Antes de proceder a ocuparnos de las propuestas concretas es preciso hacer algunas consideraciones de carácter general, que las encuadren y les den sentido.

Nos parece que lo primero que se debe de te- ner en cuenta de cara a una estrategia campesina37 es la heterogeneidad de su composición, lo cual no niega que existan problemas comunes. En consecuencia, habrá que buscar la unidad en la diversidad, pero sin olvidar esta última.

Consideramos también - aunque sea muy obvio- que es importante tener siempre presente la necesidad de seguir avanzando en la organización de los campesinos, bajo la modalidad que más se ajuste a sus características particulares. Así, por ejemplo, la asociación para los trabajadores sin tierra, la cual a futuro podría transformarse en alguna modalidad sindical; la cooperativa, ya sea sociedad o asociación, para los trabajadores agrícolas con activos; la federación para las cooperativas ya existentes y la confederación para las federaciones no confederadas. Es igualmente importante seguir creando nuevas asociaciones comunales, así como fortaleciendo las ya existentes.

Nos parece de suma importancia interiorizar la trascendencia que tiene el agro de cara a la problemática ecológica, lo cual ha llevado a una concepción de desarrollo agroecológica, que busca rescatar, preservar y fomentar la relación armónica entre el hombre y la naturaleza38.

De igual manera, debe de tenerse presente el enfoque de género, pero sin perder de vista que éste se encuentra entrecruzado con la problemática de los intereses de clase, los cuales, por más que se busque acallarlos, no dejan de estar presentes en la realidad social, jurídica, económica y política del país y del agro en particular39.

También consideramos de suma trascendencia que en su actividad reivindicativa, el movimiento campesino agote las instancias enmarcadas dentro del derecho y genere la suficiente opinión pública favorable a sus demandas, de tal manera que, si fuera necesario llegar a las acciones de hecho, cuente con suficiente apoyo de los distintos sectores sociales y políticos para evitar así las medidas represivas de parte del gobierno, o en todo caso, que éste tenga que cargar con los costos políticos de sus acciones impopulares.

Las recientes tomas de tierras deberían permitirnos sacar algunas conclusiones, ya que pese a todo el derecho que asistía a los compañeros campesinos, el balance arroja saldos negativos y positivos. Nos parece que los saldos negativos, como las reformas a los códigos Penal y Procesal Penal, 
pudieron haberse evitado si primero se hubiese generado una opinión pública favorable a las exigencias de los campesinos. Si les asiste todo el derecho, tal como lo evidencia la Asociación Democrática Campesina en su pronunciamiento, lo conveniente hubiese sido dejar las medidas de hecho para un segundo momento, demandando primero al Organo Judicial, llevando a cabo marchas pacíficas y haciendo publicaciones razonadas. De esta forma, se hubiera podido crear conciencia en los diferentes sectores de la vida nacional sobre la intransigencia del gobierno al no proceder a transferir las tierras que superan las 245 hectáreas permitidas por la Constitución.

Dicho todo lo anterior, proponemos promover y consolidar las diferentes formas organizativas de los trabajadores del campo como única alternativa para ser auténticos sujetos de sus procesos y sus proyectos.

Potenciar el trabajo de la Alianza Democrática Campesina y promover una mayor incorporación a la misma de todas las organizaciones campesinas. La división de los trabajadores sólo favorece a sus enemigos.

Establecer o fortalecer los vínculos con organizaciones de trabajadores del área, tales como la Asociación de Organizaciones de Productores Agropecuarios para la Cooperación y el Desarrollo (ASOCODE), la Coordinadora Centroamericana de Trabajadores (COCENTRA), etc., a fin de ganar en fortaleza y experiencias.

Cobrar conciencia del carácter depredador del sistema capitalista y de la profundización del mismo con la implementación de las políticas neoliberales. De allí que el trabajador del campo debe constituirse en vanguardia del movimiento por la vida, exigiendo e implementando programas de defensa del medio ambiente. Para ello es preciso buscar apoyo financiero en organismos internacionales que posibiliten el "desarrollo agroecológico sostenible".

"Promover el mejoramiento de la calidad de vida de la población rural por medio de un proceso participativo" 40 , no discriminatorio en razón del sexo, ni depredador del medio ambiente.
Propiciar la seguridad alimentaria nacional y, en consecuencia, demandar al gobierno la implementación de políticas agropecuarias orientadas a tal fin: créditos en condiciones favorables, asistencia técnica gratuita, medidas de protección arancelarias y no arancelarias.

Exigir la transferencia de tierras de todas las propiedades que exceden a las 245 hectáreas, así como el cumplimiento total del programa de transferencia de tierras derivado de los acuerdos de paz.

Crear, mediante la ayuda de organismos internacionales, una institución para apoyar la diversificación de la producción agropecuaria campesina, así como la comercialización nacional $\mathrm{e}$ internacional de la misma. O sea que el productor campesino conozca qué productos son más rentables en la actualidad, cómo producirlos - si fuera el caso-y a su vez, cómo venderlos directamente. Un ejemplo de estos nuevos productos es la marigold o flor amarilla.

Los trabajadores asalariados 41 deben exigir una actualización de los salarios mínimos, de tal manera que éstos basten, al menos, para satisfacer la canasta básica ampliada rural del Ministerio de Planificación.

Asimismo, deben promover y fortalecer las asociaciones campesinas, mientras no se consiga la sindicalización de los trabajadores del campo.

Deben buscar la conformación de una sola asociación de campesinos asalariados o central de trabajadores campesinos asalariados, para tener capacidad de incidir en el establecimiento de los salarios mínimos rurales, así como en otras decisiones gubernamentales que los afecten.

Demandar la sindicalización campesina como un derecho de los trabajadores del campo, puesto que no existe ninguna justificación económica, ni ética para mantener discriminado a un sector importante de la población.

Los trabajadores organizados en cooperativas deben luchar por la condonación de la deuda agraria.

Deben defender las cooperativas como una modalidad de propiedad y trabajo con mayores po- 
tencialidades para sacar a los trabajadores del agro de su condición de pobreza secular, ante los intentos de parcelación por parte del gobierno, tal como es el caso del Decreto 14.

Fortalecer la educación cooperativa y el espíritu comunitario como una defensa ante el individualismo, pregonado por la visión neoliberal.

Asimismo, deben fortalecer la capacidad de gestión empresarial en las cooperativas, entendiendo por tal, todo lo relacionado con la gestión de recursos financieros, la administración, la producción, la comercialización, etc., así mejorará la eficiencia y la productividad y resistirán la arremetida del modelo neoliberal.

Deben promover los cultivos orgánicos e insertarse en las cadenas de "comercio alternativo" como parte de una estrategia de exportaciones directas, a fin cle lograr mejores precios para sus productos.

Podrían avanzar en los procesos de agro-industrialización, diversificación de la producción agropecuaria y cierre de las cadenas de valor agregado, todo lo cual exige de una fuerte dosis de coordinación en el sector cooperativo ${ }^{42}$.

Promover la conformación de un banco cooperativo o apoyar otros esfuerzos en este sentido, como medida de defensa ante la exclusión y voracidad de la banca comercial.

Introducir en las cooperativas pequeños talleres artesanales de producción de bienes de consumo final o bien medios de trabajo. Con esto no sólo se lograría depender menos del mercado capitalista, sino que a su vez se generaría empleo en los meses que no hay actividad agrícola.

Las comunidades deben preservar y desarrollar el espíritu comunitario.

En esta misma línea, deben legalizar las asociaciones comunales en aquellos casos en que aún se haya obteniclo la personería jurídica.

Se debe conformar una organización nacional que aglutine a las distintas comunidades de repobladores y repatriados. De esta manera, las arbitrariedades y la intransigencia del gobierno serían enfrentadas por un bloque.

Conviene establecer o ampliar las relaciones sociales, líticas, culturales y, principalmente, económicas con otras comunidades, con el movimiento cooperativo nacional y con los trabajadores or- ganizados del campo y de la ciudad.

Al gobierno se le deben exigir los servicios sociales e infraestructurales necesarios para mejorar las condiciones de vida y de trabajo en las comunidades.

Asimismo, se le debe exigir el cumplimiento de los acuerdos de paz en materia de transferencia de tierras.

\section{Notas}

1. El presente artículo es parte de una investigación mayor realizada para UITA.

2. E. Galdámez y A. Goitia en "El movimiento campesino en El Salvador: evolución y lucha", Revista Realidad Económico Social, Universidad Centroamericana "José Simeón Cañas", noviembre-diciembre, 1993. Este artículo se ha utilizado como fuente de la información relativa a los antecedentes del movimiento campesino.

3. Se dice que surgió con fuertes vinculaciones formales y orgánicas con la $A F L-C I O$ (American Federation Labor-Congress of Industrial Organization) y la AID (Agencia Internacional para el Desarrollo). Esa es la opinión de J. J. García, citada por E. Galdámez y A. Goitia en "El movimiento campesino en El Salvador: evolución y lucha", ya citado.

4. Además de la Federación de Sindicatos de la Construcción, del Transporte y Similares (FESINCONSTRANS), el Sindicato Unión de Trabajadores de la Construcción (SUTC) y el decorativo Partido Unionista Centroamericano.

5. Entre sus demandas vinculadas con el campesino se encuentran el aumento de salarios, la ejecución de la segunda fase de la reforma agraria y la exoneración del pago de la deuda agraria a las cooperativas del sector reformado.

6. La Central de Trabajadores del Campo (CTS) había sido parte integrante de la Unidad Popular Democrática, pero entonces apareció como independiente y aportando, quizá, la mayor base social con aproximadamente 44 mil miembros.

7. Además integraron la Unión Nacional de Obreros y Campesinos: la Confederación General de Trabajadores (CGT), la Confederación de Trabajadores Democráticos (CTD), la Federación de Sindicatos de la Construcción, Transporte y Similares (FESINCONSTRANS).

8. La cual siguió creciendo pese al retiro de la Unidad Popular Democrática, aunque en la actualidad pareciera que pasa por una crisis de recomposición.

9. Actualmente la UNOC ha desaparecido del escenario político-social, luego de algunas divisiones y deserciones, pero dados sus vínculos históricos con el IADSL, podría resurgir en cualquier momento gra- 
cias al apoyo pecuniario del mismo.

10. Folleto de divulgación de la Alianza Democrática Campesina.

11. Programa de Formación en Seguridad Alimentaria, "Temas de las organizaciones de pequeños y medianos productores de Centroamérica", No. 6, CADESCA-CCE-Gobierno de los Países Bajos.

12. Como veremos más delante, el mayor número de integrantes de la Alianza Democrática Campesina es cooperativista.

13. Folleto de divulgación de la Unión Comunal Salvadoreña.

14. Ibid.

15. La conflictividad ha sido tal que la Unión Comunal Salvadoreña, al pie del listado de los integrantes del consejo ejecutivo nacional, publicado por ella misma, se lee: "Según resolución de la dirección de asesoría legal del Ministerio del Interior, abril de 1994".

16. Folleto de divulgación de la Central de Trabajadores del Campo.

17. Folleto de divulgación de la Confederación de Federaciones de Cooperativas de la Reforma Agraria Salvadoreña.

18. Folleto de divulgación de la Federación Salvadoreña de Cooperativas de la Reforma Agraria.

19. Folleto de divulgación de FEDECOOPADES.

20. Folleto de divulgación de la Corporación de Comunidades Rurales para el Desarrollo de El Salvador e investigación de campo.

21. Por campesino proletario entendemos aquel que parte del año trabaja para sí mismo, en una parcela menor de 2 hectáreas, de muy baja calidad agricola y que generalmente cultiva granos básicos. Pero además, se ve en la necesidad de vender su fuerza de trabajo durante otra parte del año. En cambio el proletario agrícola es aquel que sólo vive de la venta de su fuerza de trabajo, ya sea de manera permanente o temporal.

22. Los beneficiarios, cuando la fuente lo registra, han sido estimados a partir de un promedio familiar de cinco miembros.

23. ANTA en reciente publicación decía tener 12 mil afiliados; sin embargo, en la investigación establecimos los siguientes datos: 11,947 afiliados individuales y 4,500 socios de 52 cooperativas inscritos en el Departamento de Asociaciones Agropecuarias.

24. Se registra como afiliada a FECOIAS, la cual está integrada en CONFRAS. Además de las cooperativas, posee asociados individuales.

25. Otras fuentes menos confiables hablan de $13 \mathrm{mil}$ socios y 160 cooperativas.

26. Realmente, el número de asociados individuales que esta asociación dice tener parece ser bastante exagerado y quizá sea una mera estimación del número de indígenas que cuentan con algún tipo de organización a nivel nacional.

27. El número de socios es estimado, ya que la información que brindaron está referida sólo a las 35 cooperativas y a las 89 organizaciones comunales.

28. Registra 17 cooperativas y 876 afiliados individuales.

29. Registra 25 cooperativas tradicionales, un número no determinados del sector reformado $y$ "finateros".

30. A su vez, FEDECOOPADES atiende a 20 cooperativas no afiliadas, 3 grupos precooperativos y 4 comunidades, de allí que el número de beneficiarios lo estime en 24 mil personas.

31. La información corresponde exclusivamente al VIII Censo de la reforma agraria, Fase I, 1991-1992.

32. Ibid.

33. Cooperativas de la reforma agraria, Fase I. Los datos corresponden al VIII Censo de cooperativas del sector agropecuario reformado, 1991-1992. En el siguiente censo ya no se obtuvo esta información.

34. CRIPDES aglutina a 168 comunidades rurales en 32 municipios, en nueve de los catorce departamentos del país. No tiene presencia en los tres departamentos de la zona occidental ni en Morazán y La Unión.

35. Sindicato de la Industria Nacional del Azúcar con seccionales en los ingenios Jiboa, La Cabaña, Chaparrastique, La Magdalena, El Carmen y Chanmico.

36. En opinión de ADC y ANTA son 220 mil familias sin tierra. Diario Latino, 27 de octubre de 1995.

37. El calificativo está usado en sentido general para referirse a los trabajadores y a las trabajadoras agrícolas.

38. Ver O. Núñez et al., Desarrollo agroecológico y asociatividad campesina. Managua, CIPRES, 1995.

39. Una muestra clara de lo anterior son las reformas a los códigos Penal y Procesal Penal, a fin de encarcelar a quienes propongan, promuevan $o$ instiguen la ocupación de tierras.

40. Ibid., p. 46.

41. Aquí se combinan propuestas para el proletario agrícola y el campesino proletario, ya que la realidad es así de compleja.

42. Ver mis trabajos: "El sector agropecuario reformado y la nueva economía popular", Revista Realidad Económico Social, mayo-junio, 1992 y La Nueva Economía Popular: una aproximación teórica, UCA Editores, 1993. 